\title{
BMJ Open Levels, trends and reasons for unmet need for family planning among married women in Botswana: a cross-sectional study
}

\author{
Gobopamang Letamo, Kannan Navaneetham
}

To cite: Letamo G, Navaneetham K. Levels, trends and reasons for unmet need for family planning among married women in Botswana:

a cross-sectional study. BMJ Open 2015;5:e006603. doi:10.1136/bmjopen-2014006603

- Prepublication history for this paper is available online. To view these files please visit the journal online (http://dx.doi.org/10.1136/ bmjopen-2014-006603).

Received 15 September 2014 Revised 3 March 2015 Accepted 5 March 2015

CrossMark

Department of Population Studies, Faculty of Social Sciences, University of Botswana, Gaborone, Botswana

\section{Correspondence to} Dr Gobopamang Letamo; letamog@mopipi.ub.bw

\section{ABSTRACT}

Objectives: The objectives of this study are: (1) to estimate the prevalence of unmet need for family planning among married women using Botswana Family Health Survey 2007 data and (2) to identify risk factors for unmet need for family planning among married women.

Design: This study used secondary data from a crosssectional survey that was conducted to provide a snapshot of health issues in Botswana.

Setting: Nationally representative population survey data. Participants: 2601 married or in union women aged 15-49 years who participated in the 2007 Botswana Family Health Survey were included in the analysis. Primary outcome: Unmet need for family planning, which was defined as the percentage of all fecund married women who are not using a method of contraception even though they do not want to get pregnant.

Results: Married women who had unmet need for family planning were $9.6 \%$ in 2007. Most of the unmet need was for limiting $(6.7 \%)$ compared to spacing $(2.9 \%)$. Unmet need for family planning was more likely to be among women whose partners disapproved of family planning, non-Christians, had one partner and had never discussed family planning with their partner. Women of low parity, aged 25-34 years, and greater exposure to mass media, were less likely to have experienced unmet need. The patterns and magnitude of covariates differed between unmet need for limiting and for spacing.

Conclusions: The prevalence of unmet need for family planning was low in Botswana compared to other subSaharan African countries. The findings from this study reemphasise the importance of women's empowerment and men's involvement in women's sexual and reproductive healthcare needs and services. Different approaches are needed to satisfy the demand for family planning for spacing and limiting.

\section{INTRODUCTION}

One of the critical issues articulated at the International Conference on Population and Development is the basic right of all couples and individuals, to decide freely and responsibly, the number and spacing of their

\section{Strengths and limitations of this study}

- This is the first study in recent years to estimate the extent of unmet need for family planning in Botswana in the context of high HIV/AIDS prevalence.

- The study used the revised unmet need algorithm developed by DHS.

- The study also unravelled the important determinants of unmet need for family planning among married women.

- A limitation is that the study was unable to distinguish between couples use of contraception either for not wanting children or HIV prevention because of lack of data.

children, and to have the information, education and means to do so. ${ }^{1}$ To achieve this right, provision of access to voluntary family planning (FP), especially effective contraceptive methods, for women and men is imperative. FP is not only crucial to directly improve reproductive health outcomes, but is also positively associated with improvements in health, schooling and economic outcomes. ${ }^{2}$ Because of its importance, this right has been incorporated into the achievement of universal access to reproductive health-a target in Millennium Development Goal (MDG) 5 to improve maternal health-and indicates the investments needed and progress expected from programmatic efforts to expand access to effective contraceptive methods. ${ }^{3}$

The 2012 London Summit on FP reinvigorated interest and commitment to $\mathrm{FP}^{4}{ }^{4}$ The summit raised a number of questions: Which women and girls have an unmet need for modern contraceptives? Can unmet need be eliminated solely by increasing access to contraceptives? Whose unmet needs are most pressing, and which strategies should be prioritised? These questions should guide future research regarding FP. 
Unmet need points to the gap between women's reproductive intentions and their contraceptive behaviour. Unmet need is a valuable indicator for national FP programmes because it shows how well they are achieving a key mission: meeting the population's felt need for FP. ${ }^{5}$ It has been observed that data on unmet need can help FP programmes target activities by identifying women who are at greatest risk of unintended pregnancy and more likely to adopt methods than other non-users. ${ }^{6}$ In addition, the concept of unmet need places women's personal reproductive preferences, rather than numerical targets for fertility and population growth, at the centre of FP services. ${ }^{6}$

Although the government did not articulate a National Population Policy until 1997, from the outset it showed commitment to meeting the FP needs of the people of Botswana by establishing the maternal and child health/FP (MCH/FP) unit in $1973 .^{7}$ The unit integrated FP programme into primary healthcare, using the vast network of health facilities in rural and urban areas, which made FP services readily available. ${ }^{8} 9$ Currently, FP exists as a subunit in the Department of Sexual and Reproductive Health Division. ${ }^{9}$ Public health facilities, which are widely spread throughout the country, and have been providing FP and MCH services since $1973 .{ }^{9}$ After the integration of FP into primary healthcare in 1984, FP services have been offered daily at public health facilities, particularly at the lower level health facilities where most FP visits take place. ${ }^{9}$ Modern contraceptives currently available at the health facilities are oral contraceptives, male condoms, female condoms, injectables (Depo-Provera), intrauterine devices (IUDs; Copper T), male sterilisation and female sterilisation. ${ }^{9}$ Norplant was piloted but never approved as part of available contraceptive methods offered. Therefore, overall, women have a full range of methods to choose from and therefore low levels of unmet need would be expected.

Because of the strong FP programme, the use of modern contraceptives increased over the past three decades, rising from $16 \%$ in 1984 to $29 \%$ in $1988,40 \%$ in $1996,42 \%$ in 2000 and $51 \%$ in $2007 .{ }^{9}$ FP clients relied on three main methods of contraception: male condoms, oral contraceptives and Depo-Provera. Patterns of condom use in Botswana show that in 1984, only $1 \%$ of all women aged 15-49 years reported using a male condom and this figure rose to $1.3 \%$ in $1988,11.3 \%$ in $1996,15.5 \%$ in 2000 and, finally, to $41.6 \%$ in $2007 .{ }^{9}$ The use of female condoms is almost non-existent. The World Bank study shows that the use of oral contraceptives, which stood at $8.5 \%$ in 1984, increased to $17.7 \%$ in 1988 and 1996, but thereafter declined to $14.3 \%$ in 2000 and $6.1 \%$ in 2007 . The study shows that the use of injectables was $1.1 \%$ in 1984 , increased to $3.2 \%$ in 1988 , to $5.7 \%$ in 1996 , to $8.1 \%$ in 2000 and then declined to $6.8 \%$ in $2007 .^{9}$

Since 2014 is the 20th anniversary of the Programme of Action of the International Conference on Population and Development, and 2015 is the end of the MDGs, the question: what progress has been made in ensuring that all couples and individuals, decide freely and responsibly, the number and spacing of their children, and have the means to do so, is imperative. It has been observed with reference to Botswana that currently, no data are available on the unmet need for FP or unintended pregnancies. ${ }^{10}$ To the best of our knowledge, no previous study except a study by Westoff and Ochoa ${ }^{11}$ has documented the prevalence and factors affecting unmet need for FP in Botswana. This article is expected to provide the stakeholders and programme managers with fundamental data necessary for monitoring and intervention to improve the reproductive health in Botswana. The purpose of this study, therefore, is to: (1) estimate the prevalence of unmet need for FP among married women; (2) establish the levels and trends in unmet needs for FP among married women; (3) reasons for non-use of contraception among women with unmet need; and (4) identify risk factors for unmet need for FP among married women.

\section{METHODS}

\section{Study design}

This is a cross-sectional survey that was conducted to provide a snapshot of health issues in Botswana. The Botswana Family Health Survey IV (BFHS IV) was conducted in September 2007-January 2008 by the Central Statistics Office in close collaboration with UNICEF. The Multiple Indicator Cluster Survey was combined with the BFHS IV because of the similarity of the indicator modules. Four questionnaires were administered, namely the Household Questionnaire, Female Questionnaire (administered to females aged 12-49), Male Questionnaire (administered to males aged 12-49) and the Under 5 Questionnaire. $^{12}$

\section{Participants}

For this study, 2601 women respondents aged 15-49 years were selected for the analysis. In the context of Botswana, unmet need for FP is calculated for women who were married or in union at the time of the survey, using the revised definition as described by Bradley et $a .^{13}$ In this paper, we refer to married women as those married and those living with their partner at the time of the survey.

\section{Outcome variable}

\section{Unmet need for FP}

Unmet need for FP was defined as the percentage of all fecund married women or women living with a sexual partner and not using a method of contraception even though they do not want to get pregnant. As in previous studies, married women and women living with their sexual partners were assumed to be sexually active. It also included pregnant and amenorrheic women for whom pregnancy or giving birth was unwanted or mistimed. The concept of unmet need reflects the gap 
between childbearing desires and contraceptive use. We computed unmet need for FP using the Bradley et $a l^{13}$ model.

\section{Calculating demand for FP and proportion of demand satisfied or not satisfied}

We follow the convention of referring to the percentage of women with an unmet need plus the percentage currently using contraception (representing 'met need') as demand for FP, and referring to the percentage of women using contraception divided by the percentage of women with demand for FP as the proportion of demand satisfied. The demand not satisfied is measured by the proportion of women with unmet need divided by the total contraceptive demand (the proportion of women with unmet need or using contraceptives).

\section{Exposure variables}

A range of individual and household-level variables were used, based on the theoretical and empirical research derived from the international literature, and they reflect different dimensions of contraceptive decisionmaking and preference for number of children, and, thus, unmet need for FP. The individual-level variables that are included in the study are age, parity, education and access to media, for instance, radio or television. The variables such as age and parity will give insight on the effect of different life course stages on the couples' contraceptive decision-making. Educated women may have greater awareness on the range of contraception methods available and may also have greater autonomy in decision-making than uneducated women. Exposure to electronic media is an important source of information about the range of contraceptive methods.

Male involvement in decision-making on the use of contraception is an important factor on the unmet need for contraception. The study included two other individual-level variables: perceived partner's approval of contraception and partners' discussion of FP. These variables not only reflect the women's empowerment but also the nature of the relationship with the partner in terms of decision-making. The household-level variables such as religion and wealth status were also included. Decision-making on the use of contraception is likely to vary by religion due to differences in cultural practices and beliefs. The unmet need for FP is likely to vary by wealth status as the rich may have greater capability to access FP services than the poor. The place of residence was included as community-level variable. The availability and accessibility of FP services are likely to be different between rural and urban areas, due to differences in health and FP infrastructure.

\section{Statistical analysis}

Data were analysed using SPSS software, V.21. Contingency tables and percentages were used to assess the relationship between unmet need and relevant sociodemographic variables. Binary logistic regression analysis was used to determine risk factors for unmet need for FP. Unmet need for FP, a dichotomous variable, was the dependent variable and individual, household and community characteristics were independent variables. A multinomial logistic regression model was also used to determine how the covariates vary between the unmet need for spacing and unmet need for limiting.

\section{RESULTS}

\section{Levels of unmet need for FP among married women}

Figure 1 shows the distribution of unmet need for modern FP by various groups of married women. From this figure, it is evident that of the $30.3 \%$ of married women not using modern contraception, $5.5 \%$ were pregnant or postpartum amenorrheic and $24.8 \%$ were not pregnant or postpartum amenorrheic.

The percentage of married women with unmet need for FP in Botswana was estimated to be $9.6 \%$ in 2007. Out of the $9.6 \%$ of unmet need, $2.9 \%$ was unmet need for spacing and the remaining $6.7 \%$ was unmet need for limiting. Given that the contraceptive prevalence rate among married women was $69.7 \%$ in 2007 , the total percentage of demand satisfied was $87.9 \%$, implying that $12.1 \%$ of the demand for FP was not satisfied.

\section{Unmet need of married women by background characteristics}

Table 1 presents unmet need for FP by married women's characteristics. Unmet need for FP was highest among rural compared with urban residents $(11.9 \%$ vs $8.1 \%$ respectively). Unmet need was also high in women who wanted to limit among married women living in rural and urban areas, $9 \%$ and $5.3 \%$, respectively.

As regards educational attainment, unmet need was highest among married women with no education (20.1\%) compared with women with secondary education $(6.0 \%)$. About $16.2 \%$ of women with primary education had unmet need while those with postsecondary education had $7.1 \%$ of unmet need for FP. A similar pattern was observed among women with unmet need for limiting. However, women with secondary education or primary education had the highest unmet need for spacing of $3.1 \%$ compared to $1.7 \%$ for women with tertiary education.

As expected, unmet need for FP increases with increasing parity. The highest unmet need was observed among married women with a parity of five or more $(21 \%)$. A similar pattern was observed among women with unmet need for limiting, where women with zero parity had the lowest unmet need $(0.7 \%)$ and women with a high parity of five and above had the highest unmet need for limiting (19.7\%). However, unmet need for spacing declined with increasing number of children ever born. Zero parity women had $4.8 \%$ of unmet need for spacing compared to $1.3 \%$ of unmet need for spacing among married women of parity five or more. 


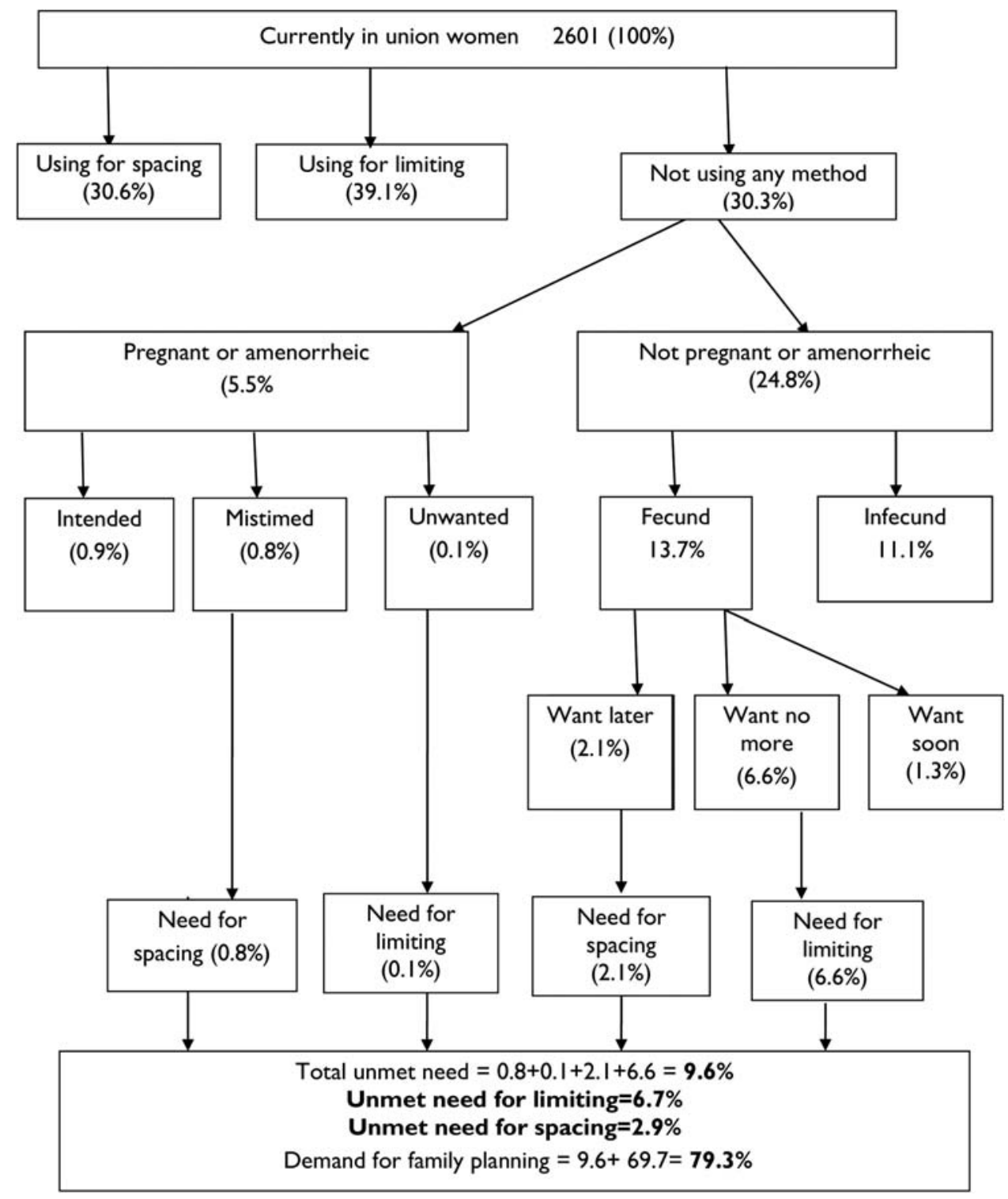

Figure 1 Unmet need for contraception among married women, Botswana, 2007.

Married women aged 35-49 had the highest unmet need for FP compared with women aged 25-34 years, $14.7 \%$ and $5.5 \%$, respectively. The highest unmet need for limiting was observed among women aged 35-49 years and the lowest among those aged 25-34 years, $12.8 \%$ and $3.0 \%$, respectively. Unmet need for spacing decreased with increasing age of women.

Wealth also influenced unmet need for FP. Married women from the poorest quintile had the highest unmet need for FP (16.6\%) while the richest women had the lowest unmet need $(7.1 \%)$. As regards unmet need for limiting, the poorest women had the highest unmet need compared with the richest, $12.9 \%$ and $4.8 \%$, respectively. No clear pattern emerged with regard to unmet need for spacing and wealth status.

Unmet need for FP was lowest among Christians $(8.9 \%)$ and highest among non-Christians (12.7\%). Unmet need for limiting and spacing were also lowest among Christians and highest among non-Christians.
Unmet need for FP was almost twice as high for married women with one partner compared with women with more than one partner. Similar patterns were observed in unmet need for limiting and spacing.

Married women who had never discussed FP with their partner had the highest unmet need for FP compared with women who discussed FP more often, 16.2\% and $7.3 \%$, respectively. The higher the frequency of the discussion of FP with a partner the lower the unmet need for FP. This was true in unmet need for limiting and spacing.

Women whose partners disapproved of FP had the highest unmet need for FP, $16.5 \%$ and $7.5 \%$, respectively. The pattern was also observed for unmet need for limiting and spacing. Mass media influenced unmet need for FP. Women who did not listen to a radio and who did not watch television in the past week had the highest unmet need for FP, $15.7 \%$ and $14.1 \%$, respectively. A similar pattern was observed for unmet need for 
Table 1 Unmet need for FP by married women's characteristics, Botswana, 2007

\begin{tabular}{|c|c|c|c|c|}
\hline \multirow[b]{2}{*}{$\begin{array}{l}\text { Background } \\
\text { characteristics }\end{array}$} & \multicolumn{3}{|c|}{ Unmet need for FP (\%) } & \multirow[b]{2}{*}{ Women $(\mathrm{n}$} \\
\hline & $\begin{array}{l}\text { For } \\
\text { spacing }\end{array}$ & $\begin{array}{l}\text { For } \\
\text { limiting }\end{array}$ & Total & \\
\hline \multicolumn{5}{|l|}{ Residence } \\
\hline Rural & 2.9 & 9.0 & 11.9 & 1001 \\
\hline Urban & 2.8 & 5.3 & 8.1 & 1600 \\
\hline \multicolumn{5}{|l|}{ Education } \\
\hline No education & 2.2 & 17.9 & 20.1 & 179 \\
\hline Primary & 3.1 & 13.1 & 16.2 & 612 \\
\hline Secondary & 3.1 & 2.9 & 6.0 & 1399 \\
\hline Higher & 1.7 & 5.4 & 7.1 & 410 \\
\hline \multicolumn{5}{|l|}{ Parity } \\
\hline 0 & 4.8 & 0.7 & 5.5 & 273 \\
\hline $1-2$ & 3.5 & 3.6 & 7.1 & 1226 \\
\hline $3-4$ & 1.8 & 7.6 & 9.4 & 719 \\
\hline $5+$ & 1.3 & 19.7 & 21.0 & 371 \\
\hline \multicolumn{5}{|l|}{ Age (years) } \\
\hline $15-24$ & 5.3 & 3.5 & 8.8 & 509 \\
\hline $25-34$ & 2.5 & 3.0 & 5.5 & 1112 \\
\hline $35-49$ & 1.9 & 12.8 & 14.7 & 967 \\
\hline \multicolumn{5}{|l|}{ Wealth index } \\
\hline Poorest & 3.7 & 12.9 & 16.6 & 435 \\
\hline Poorer & 1.9 & 9.2 & 11.1 & 262 \\
\hline Middle & 2.6 & 6.0 & 8.6 & 605 \\
\hline Richer & 3.6 & 4.3 & 7.9 & 611 \\
\hline Richest & 2.3 & 4.8 & 7.1 & 689 \\
\hline \multicolumn{5}{|l|}{ Religion } \\
\hline Christianity & 2.7 & 6.2 & 8.9 & 2154 \\
\hline Others & 3.6 & 9.1 & 12.7 & 441 \\
\hline \multicolumn{5}{|c|}{ Number of partner } \\
\hline One & 3.1 & 7.3 & 10.4 & 2163 \\
\hline More than one & 1.6 & 3.7 & 5.3 & 438 \\
\hline \multicolumn{5}{|c|}{ Discussion on FP with partner } \\
\hline Never & 3.4 & 12.8 & 16.2 & 499 \\
\hline One or two times & 3.0 & 7.3 & 10.3 & 627 \\
\hline More often & 2.7 & 4.6 & 7.3 & 1392 \\
\hline \multicolumn{5}{|c|}{ Partner's approval of FP } \\
\hline Approve & 2.4 & 5.1 & 7.5 & 2191 \\
\hline Disapprove & 6.7 & 19.2 & 16.5 & 328 \\
\hline \multicolumn{5}{|c|}{ Listen to radio once in a week } \\
\hline Yes & 2.9 & 4.9 & 7.8 & 2000 \\
\hline No & 2.8 & 12.9 & 15.7 & 599 \\
\hline \multicolumn{5}{|c|}{ Listen to TV once in a week } \\
\hline Yes & 2.8 & 4.5 & 7.3 & 1726 \\
\hline No & 3.0 & 11.1 & 14.1 & 875 \\
\hline Total & 2.9 & 6.7 & 9.6 & 2601 \\
\hline
\end{tabular}

limiting. However, unmet need for spacing was virtually the same for women who did not listen to a radio and who did not watch television in the past week.

Trends in unmet need, demand for FP and demand satisfied of married women

Table 2 shows trends in total demand for contraception and its components for married women in Botswana between 1988 and 2007. From the table, it can be
Table 2 Trend in total demand for contraception and its components for currently married women, Botswana, 1988 and 2007

\begin{tabular}{lrr}
\hline Demand for contraception & $\mathbf{1 9 8 8}^{*}$ & $\mathbf{2 0 0 7}$ \\
\hline Unmet need for (\%) & & \\
$\quad$ Spacing & 19.4 & 2.9 \\
$\quad$ Limiting & 7.4 & 6.7 \\
$\quad$ Total & 26.9 & 9.6 \\
Current use for (\%) & & \\
$\quad$ Spacing & 17.9 & 30.6 \\
$\quad$ Limiting & 15.1 & 39.1 \\
$\quad$ Total & 33.0 & 69.7 \\
Total demand for (\%) & & \\
$\quad$ Spacing & 38.6 & 33.5 \\
$\quad$ Limiting & 23.0 & 43.8 \\
$\quad$ Total & 61.6 & 79.3 \\
Per cent demand satisfied for & & \\
$\quad$ Spacing & 46.4 & 91.3 \\
$\quad$ Limiting & 65.7 & 85.4 \\
$\quad$ Total & 53.6 & 87.9 \\
\hline Source: Westoff and Ochoa. ${ }^{11}$ & &
\end{tabular}

observed that the demand for contraception has increased from $61.6 \%$ in 1988 to $79.3 \%$ in 2007 . The percentage of married women with unmet need for FP has decreased from $26.9 \%$ in 1988 to $9.6 \%$ in 2007 , about 17 percentage points. Almost all this decrease in unmet need was attributed to a decrease of unmet need for spacing, which dropped from $19.4 \%$ in 1988 to $2.9 \%$ in 2007 (figure 2). Unmet need for limiting dropped slightly from $7.4 \%$ in 1988 and $6.7 \%$ in 2007 , reflecting that most of the demand for contraception was for spacing rather than limiting purposes during the interval.

The contraceptive use rate has increased from $33 \%$ in 1988 to $69.7 \%$ in 2007 , as more women desire to prevent pregnancy. It should be noted that as levels of contraceptive use increased, the proportion of demand satisfied increased from $53.6 \%$ in 1988 to $87.9 \%$ in 2007 . The unsatisfied demand for FP decreased from $46.4 \%$ in 1988 to $12.1 \%$ in 2007.

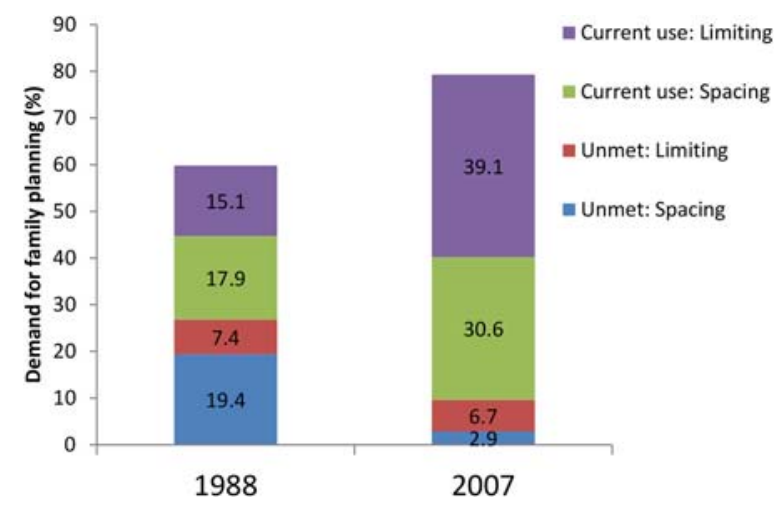

Figure 2 Demand for family planning in Botswana, 1988-2007. 
Table 3 Perceived problems with the utilisation of various modern contraceptive methods among married women with met need for family planning, Botswana, 2007 (\%)

\begin{tabular}{llllllll}
\hline Method-related perceived problems & Pill & IUD & Injection & Diaphragm & Condom & $\begin{array}{l}\text { Female } \\
\text { sterilisation }\end{array}$ & $\begin{array}{l}\text { Male } \\
\text { sterilisation }\end{array}$ \\
\hline Not effective & 6.2 & 9.9 & 3.0 & 5.9 & 13.5 & 1.9 & 1.5 \\
Partner disapproval & 1.5 & 0.3 & 0.8 & 0.7 & 2.7 & 0.5 & 0.4 \\
Side effects & 45.8 & 33.8 & 60.8 & 18.5 & 8.8 & 7.8 & 7.1 \\
Difficult to obtain & 0.2 & 0.3 & 0.2 & 0.6 & 0.2 & 0.2 & 0.2 \\
High cost & 0.2 & 0.1 & 0.0 & 0.0 & 0.3 & 0.4 & 0.5 \\
Inconvenient to use & 4.3 & 5.9 & 1.9 & 4.9 & 4.4 & 0.5 & 0.5 \\
Method permanent & 0.0 & 0.5 & 0.4 & 0.4 & 0.6 & 55.2 & 56.9 \\
None & 27.9 & 11.5 & 17.5 & 14.2 & 63.3 & 12.8 & 10.9 \\
Don't know & 14.0 & 37.7 & 15.5 & 54.8 & 6.4 & 20.6 & 21.9 \\
Total $(\mathrm{n})$ & 1763 & 1474 & 1713 & 967 & 1804 & 1206 & 996 \\
\hline
\end{tabular}

IUD, intrauterine device.

Perceived problems with various contraceptive methods among married women with unmet need and women with met need

The identification of perceptions of problems with various contraceptive methods is important in designing and implementing appropriate FP intervention strategies. Tables 3 and 4 below present the perceived problems among women with unmet compared with women with met need for the different modern contraceptive methods, respectively.

For women with unmet need and those with met need, side effects were cited as the main perceived problems with the use of pill, IUD and injection. Both groups of women also perceived the main problem with condoms to be their ineffectiveness. The women also cited the perceived problem with sterilisation to be its permanency.

The main reason for the high percentage in the 'Don't know' category reflects the limited options in the response category rather than lack of awareness about the specific method.

The predominant reason for contraceptive non-use in Botswana is the citation of health problems, with almost a third of women with unmet need reporting it. Opposition to contraception was reported as the next most important reason for contraceptive non-use among women with unmet need, standing at $26 \%$, particularly their own opposition to contraception rather than the opposition of their partner or others, $13.8 \%$ and $12.2 \%$, respectively. Inconvenience to use was cited by $18.7 \%$ of women who had unmet need for FP (figure 3).

\section{Factors influencing unmet need for contraception among married women}

The logistic regression results in table 5 show the adjusted ORs associated with total unmet need for FP. Variables that increased the likelihood of unmet need for modern contraceptives were: partner's disapproval of FP (OR=3.096; CI 2.227 to 4.310; $\mathrm{p}=0.000)$, having one partner $(\mathrm{OR}=2.000$; CI 1.259 to 3.178; $\mathrm{p}=0.003)$, never discussing FP with partner ( $\mathrm{OR}=1.355$; CI 0.955 to 1.923; $\mathrm{p}=0.089$ ) and being non-Christians ( $\mathrm{OR}=1.372$; CI 0.974 to $1.935 ; \mathrm{p}=0.071$ ).

Data in table 5 also showed being aged 25-34 years $(\mathrm{OR}=0.567$; CI 0.390 to $0.824 ; \mathrm{p}=0.003)$ and having zero parity $(\mathrm{OR}=0.454$; CI 0.225 to $0.915 ; \mathrm{p}=0.027)$ were protective factors against unmet need for FP.

Table 6 shows the multinomial regression results of the ORs associated with unmet need for spacing and

Table 4 Perceived problems with the utilisation of various modern contraceptive methods among married women with unmet need for family planning, Botswana, 2007 (\%)

\begin{tabular}{llllllll}
\hline Method-related perceived problems & Pill & IUD & Injection & Diaphragm & Condom & $\begin{array}{l}\text { Female } \\
\text { sterilisation }\end{array}$ & $\begin{array}{l}\text { Male } \\
\text { sterilisation }\end{array}$ \\
\hline Not effective & 3.6 & 5.5 & 1.5 & 5.0 & 14.0 & 2.3 & 0.9 \\
Partner disapproval & 2.3 & 0.6 & 1.0 & 0.0 & 2.6 & 0.3 & 0.0 \\
Side effects & 50.0 & 40.6 & 60.7 & 14.0 & 10.9 & 6.2 & 5.6 \\
Difficult to obtain & 0.0 & 0.0 & 0.0 & 1.0 & 0.0 & 0.0 & 0.0 \\
High cost & 0.0 & 0.0 & 0.0 & 7.0 & 0.0 & 0.0 & 0.0 \\
Inconvenient to use & 3.2 & 4.2 & 1.5 & 2.0 & 3.9 & 0.0 & 0.0 \\
Method permanent & 0.0 & 1.2 & 0.5 & 16.0 & 0.0 & 51.9 & 57.0 \\
None & 18.2 & 12.7 & 12.6 & 0.0 & 47.6 & 10.9 & 10.3 \\
Don't know & 22.7 & 35.2 & 22.3 & 55.0 & 21.0 & 28.7 & 26.1 \\
Total $(\mathrm{n})$ & 220 & 165 & 206 & 100 & 229 & 129 & 107 \\
\hline
\end{tabular}

IUD, intrauterine device. 
Figure 3 Reasons for non-use of contraception among currently married women with unmet need for contraception (FP, family planning).

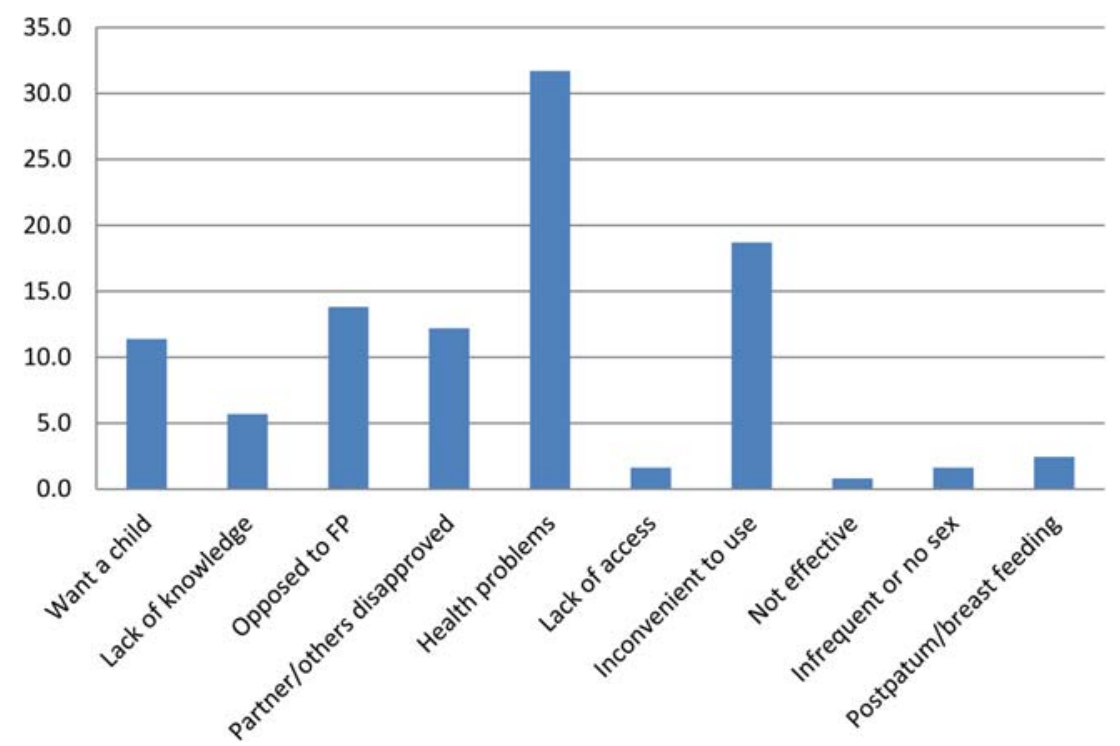

limiting separately. The increased likelihood of unmet need for spacing was observed among married women whose partners disapproved of FP $(\mathrm{OR}=4.078$; $\mathrm{p}=0.000)$, married women of zero parity $(\mathrm{OR}=3.515$; $\mathrm{p}=0.045)$, married women with one partner $(\mathrm{OR}=2.508$ $\mathrm{p}=0.022)$, married women with primary education $(\mathrm{OR}=2.901 ; \mathrm{p}=0.040)$ and married women aged 15-24 years $(\mathrm{OR}=2.228 ; \mathrm{p}=0.043)$.

Table 6 also shows that the increased likelihood of unmet need for limiting was among married women whose partners disapproved of $\mathrm{FP}(\mathrm{OR}=2.841 ; \mathrm{p}=0.000)$, married women who never discussed FP with their partners $(\mathrm{OR}=1.598 ; \mathrm{p}=0.025)$ and married women with one partner $(\mathrm{OR}=1.849 ; \mathrm{p}=0.032)$.

\section{DISCUSSION AND CONCLUSIONS}

The purpose of this study was to investigate the prevalence and correlates of unmet FP need in Botswana. The study analysed the BFHS 2007 data and included currently married or in union women who were assumed to be sexually active. The study did not include unmarried, sexually active women, as the information about their reporting of coitus within 3 months from the date of survey, which is required for revised unmet need estimates, was not available. ${ }^{13}$ However, it is expected that unmet need among unmarried women is likely to be equal or less compared with married women, as observed in sub-Saharan Africa, since only very few unmarried women, compared with married women, would want a child. ${ }^{14}$

The study results showed that unmet need for modern contraception among married women was $9.6 \%$ in 2007 , which is relatively low by African standards. The low level of unmet need in Botswana is caused by women having access to a full range of contraceptive methods. It is actually the lowest in the Southern African region. Unmet need for FP in other Southern African countries ranges between $15.5 \%$ in Zimbabwe in 2005/2006 and 26.6\% in
Zambia in 2007. ${ }^{13}$ Other Southern African countries have high unmet need of over $20 \%$ for FP. The low unmet need for FP in Botswana was also contributed to by successful implementation of the FP programme ${ }^{9}$ due to high HIV/AIDS prevalence, as a prevention strategy. Because of the large contribution to the HIV epidemic by adolescent women, who are not the same population in which high contraceptive prevalence rates are generally reported, and the fact that contraceptives other than condoms account for the vast majority of contraceptive use, high contraceptive prevalence rates have not been an indicator of low HIV prevalence in Botswana and other sub-Saharan African countries in general. ${ }^{15}$ In fact, no sub-Saharan African country with contraceptive prevalence rate of greater than $20 \%$ has an adult HIV prevalence of less than $8 \% .{ }^{15}$ Thus the increase in contraceptive prevalence rates has not necessarily translated into low HIV prevalence. It appears that as contraceptive use increases, the overall proportion of couples with unmet need falls, and this conclusion is consistent with previous research findings. ${ }^{16}$ However, greater use of condoms in preventing HIV/AIDS could have also contributed significantly to preventing pregnancy and thus a rapid fertility decline in Botswana was witnessed, from TFR of 4.2 in 1991 to 2.8 in 2011. However, no studies exist in the context of Botswana regarding how much of the decline in fertility was contributed by greater use of condoms due to high HIV prevalence and how much of it was due to a decline in the demand for children. However, studies have shown that in sub-Saharan Africa, including Uganda and Cameroon, fertility was lower among HIV-positive women. ${ }^{17}$ It should also be noted that fertility decline was already underway before the advent of HIV. Moreover, understanding the relationship between HIV prevalence and fertility has become even more complex in Botswana due to the successful antiretroviral programme in recent years.

This study found that married women with unmet need tended to be women with one partner, those who 
Table 5 Results of logistic regression analysis for total unmet need for FP among married women, Botswana, 2007

\begin{tabular}{|c|c|c|c|c|}
\hline \multirow[b]{2}{*}{ Characteristics } & \multirow[b]{2}{*}{ ORs } & \multirow[b]{2}{*}{ p Value } & \multicolumn{2}{|l|}{$95 \% \mathrm{Cl}$} \\
\hline & & & Lower bound & Upper bound \\
\hline \multicolumn{5}{|l|}{ Residence } \\
\hline Rural & 0.891 & 0.507 & 0.633 & 1.253 \\
\hline Urban & 1.000 & - & - & - \\
\hline \multicolumn{5}{|l|}{ Education } \\
\hline No education & 1.235 & 0.551 & 0.617 & 2.470 \\
\hline Primary & 1.434 & 0.205 & 0.822 & 2.505 \\
\hline Secondary & 0.815 & 0.417 & 0.497 & 1.336 \\
\hline Higher & 1.000 & - & - & - \\
\hline \multicolumn{5}{|l|}{ Parity } \\
\hline 0 & $0.454^{\star *}$ & 0.027 & 0.225 & 0.915 \\
\hline $1-2$ & $0.651^{*}$ & 0.061 & 0.415 & 1.021 \\
\hline $3-4$ & $0.672^{*}$ & 0.051 & 0.452 & 1.001 \\
\hline $5+$ & 1.000 & - & - & - \\
\hline \multicolumn{5}{|l|}{ Age (years) } \\
\hline $15-24$ & 1.104 & 0.691 & 0.678 & 1.797 \\
\hline 25-34 & $0.567^{\star \star \star}$ & 0.003 & 0.390 & 0.824 \\
\hline $35-49$ & 1.000 & - & - & - \\
\hline \multicolumn{5}{|l|}{ Wealth index } \\
\hline Poorest & 1.196 & 0.570 & 0.645 & 2.219 \\
\hline Poorer & 1.078 & 0.814 & 0.577 & 2.013 \\
\hline Middle & 1.074 & 0.785 & 0.642 & 1.797 \\
\hline Richer & 1.087 & 0.726 & 0.681 & 1.737 \\
\hline Richest & 1.000 & - & - & - \\
\hline \multicolumn{5}{|l|}{ Religion } \\
\hline Christianity & 1.000 & - & - & - \\
\hline Others & 1.372 & 0.071 & 0.974 & 1.935 \\
\hline \multicolumn{5}{|l|}{ Number of partner } \\
\hline One & $2.000^{\star \star \star}$ & 0.003 & 1.259 & 3.178 \\
\hline More than one & 1.000 & - & - & - \\
\hline \multicolumn{5}{|c|}{ Discussion on FP with partner } \\
\hline Never & $1.355^{\star}$ & 0.089 & 0.955 & 1.923 \\
\hline One or two times & 1.199 & 0.297 & 0.852 & 1.688 \\
\hline More often & 1.000 & - & - & - \\
\hline \multicolumn{5}{|c|}{ Partner's approval of FP } \\
\hline Approve & 1.000 & - & - & - \\
\hline Others & $3.096^{\star \star \star}$ & 0.000 & 2.227 & 4.310 \\
\hline \multicolumn{5}{|c|}{ Listen to radio once in a week } \\
\hline Yes & $0.647^{\star \star \star}$ & 0.008 & 0.470 & 0.892 \\
\hline No & 1.000 & - & - & - \\
\hline \multicolumn{5}{|c|}{ Listen to TV once in a week } \\
\hline Yes & 0.818 & 0.302 & 0.558 & 1.198 \\
\hline No & 1.000 & - & - & - \\
\hline
\end{tabular}

never discussed FP with their partner, and those whose partner approved of FP; these findings were consistent with findings from other countries. ${ }^{18-20}$ These results show that FP programmes need to target activities of these married women because they are at greatest risk of unintended pregnancy and more likely to adopt a method than other non-users. ${ }^{5}$

The study found that the unmet need for FP among married women declined substantially between 1988 and 2007, while the percentage of the demand satisfied among married women increased from $53.6 \%$ to $87.9 \%$ in the same period. This finding suggests that FP investments are keeping pace with the desires of married women to prevent pregnancy. The indicator measures the extent to which people are able to exercise their reproductive rights of determining the number and spacing of their children. ${ }^{21}$ Although the old algorithm of measuring unmet need would have been applied in 1988, the observed trend would decrease slightly by about 0.9 points on average. As such the trend analysis is not significantly affected by the use of different measurements of unmet need.

This study has observed the citation of health problems as the most common reason given by married 
Table 6 Results of multinomial logistic regression on unmet need for FP among married women, Botswana, 2007

\begin{tabular}{|c|c|c|c|c|}
\hline Characteristics & Spacing/others* ORs & p Value & Limiting/others† ORs & p Value \\
\hline \multicolumn{5}{|l|}{ Residence } \\
\hline Rural & 0.837 & 0.552 & 0.905 & 0.632 \\
\hline Urban & 1.000 & - & 1.000 & - \\
\hline \multicolumn{5}{|l|}{ Education } \\
\hline No education & 1.869 & 0.398 & 0.848 & 0.688 \\
\hline Primary & $2.901^{\star *}$ & 0.040 & 0.983 & 0.960 \\
\hline Secondary & 1.825 & 0.173 & $0.484^{\star \star}$ & 0.022 \\
\hline Higher & 1.000 & - & 1.000 & - \\
\hline \multicolumn{5}{|l|}{ Parity } \\
\hline 0 & $3.515^{\star \star}$ & 0.045 & $0.091^{* * *}$ & 0.001 \\
\hline $1-2$ & $3.017^{\star \star}$ & 0.046 & $0.432^{\star \star \star}$ & 0.002 \\
\hline $3-4$ & 1.590 & 0.408 & $0.631^{\star *}$ & 0.036 \\
\hline $5+$ & 1.000 & - & 1.000 & - \\
\hline \multicolumn{5}{|l|}{ Age (years) } \\
\hline $15-24$ & $2.228^{\star \star}$ & 0.043 & 0.783 & 0.468 \\
\hline $25-34$ & 1.177 & 0.638 & $0.420^{\star * \star}$ & 0.000 \\
\hline $35-49$ & 1.000 & - & 1.000 & - \\
\hline \multicolumn{5}{|l|}{ Wealth index } \\
\hline Poorest & 1.267 & 0.656 & 1.220 & 0.606 \\
\hline Poorer & 0.607 & 0.410 & 1.324 & 0.463 \\
\hline Middle & 0.889 & 0.777 & 1.211 & 0.565 \\
\hline Richer & 1.310 & 0.459 & 0.939 & 0.839 \\
\hline Richest & 1.000 & - & 1.000 & - \\
\hline \multicolumn{5}{|l|}{ Religion } \\
\hline Christians & 1.000 & - & 1.000 & - \\
\hline Others & 1.288 & 0.393 & 1.389 & 0.119 \\
\hline \multicolumn{5}{|l|}{ Number of partner } \\
\hline One & $2.508^{\star \star}$ & 0.022 & $1.849^{\star \star}$ & 0.032 \\
\hline More than one & 1.000 & - & 1.000 & - \\
\hline \multicolumn{5}{|c|}{ Discussion on FP with partner } \\
\hline Never & 0.928 & 0.821 & $1.598^{\star \star}$ & 0.025 \\
\hline One or two times & 1.040 & 0.894 & 1.302 & 0.214 \\
\hline More often & 1.000 & - & 1.000 & - \\
\hline \multicolumn{5}{|c|}{ Partner's approval of FP } \\
\hline Approve & 1.000 & - & 1.000 & - \\
\hline Disapprove & $4.098^{\star \star \star}$ & 0.000 & $2.841^{\star * *}$ & 0.000 \\
\hline \multicolumn{5}{|c|}{ Listen to radio once in a week } \\
\hline Yes & 1.099 & 0.760 & $0.522^{\star * *}$ & 0.001 \\
\hline No & 1.000 & - & 1.000 & - \\
\hline \multicolumn{5}{|c|}{ Listen to TV once in a week } \\
\hline Yes & 0.820 & 0.548 & 0.791 & 0.324 \\
\hline No & 1.000 & - & 1.000 & - \\
\hline
\end{tabular}

${ }^{*} p<0.10,{ }^{* *} p<0.05,{ }^{* * *} p<0.01$.

tOthers include contraceptive users, no unmet need, infecund and missing cases.

$\mathrm{FP}$, family planning.

women with an unmet need for not using contraception in Botswana and this conclusion is consistent with previous research work. ${ }^{18} 22$ The perceived problem mentioned by users and non-users was side effects and this finding is consistent with studies in Kenya and Tanzania. ${ }^{23} 24$ This poses a great challenge of discontinuation of methods by users and adoption of methods by non-users. Although knowledge of modern contraceptive methods is high in Botswana, it seems that myths and misconceptions persist. The exaggeration of side effects might be the influence of others' perception in the community propagated by hearsay. ${ }^{23}{ }^{24}$ In order to address this barrier, women and community need correct information on contraceptive methods and innovative strategies, to nullify the myths and misconceptions, especially about health problems. Women need to be counselled on the full range of available contraceptive methods so that they can choose the method that best matches their individual circumstances and intentions, and can change methods when they need to. ${ }^{21}$ Unless this problem is addressed, availing modern forms of contraception would not help FP programme managers to address unmet need for these women. There is need to strengthen the information, education and 
communication campaigns, and behavioural change communication programmes, to generate demand for FP services.

One of the major factors determining unmet need for FP among married women was partner's disapproval and discussion of FP. Partner's disapproval and discussion of FP were not just key determinants for total unmet need among married women, but also for spacing and limiting. As such, programmes should focus on men as well as women in order to create an environment in which both sexes can seek services and they should encourage men to discuss FP with their wives. ${ }^{25}$ These findings re-emphasise the importance of women's empowerment and men's involvement in women's sexual and reproductive healthcare needs and services.

The total fertility rate according to the 2011 population and housing census of Botswana was estimated at 2.8 per woman, ${ }^{26}$ declined from 3.3 per women in 2001 , implying that fertility is already below the target of 3 children per woman. The effect of HIV/AIDS on the fertility decline in the context of Botswana is unknown. The greater challenge for the government is to further improve the efficiency of the FP programme to meet the unmet need for contraception and keeping the total fertility rate at 3 children per woman, according to the 2010 Revised National Population Policy of Botswana, ${ }^{27}$ and at the same time reducing the HIV/AIDS incidence and maternal mortality. The government may explore the possibility of developing a policy that encourages the demand for children, to maintain TFR at 3, while at the same time ensuring that the HIV incidence is kept low if not eliminated. The setting of targets has often been criticised by women's rights advocates arguing that it promotes a coercive attitude towards women, who are viewed as targets for meeting administratively mandated counts of contraceptive acceptors rather than as individuals in need of health and FP services. $^{28}$ It is argued that programmes are run according to targets and quotas, tending to forget about the quality of services and instead worrying only about meeting numerical goals. ${ }^{28}$ Since the International Conference on Population and Development of 1994, the emphasis of FP is on meeting the sexual and reproductive needs of women and, as such, the quality of services is very critical in FP programmes. Since the problem of side effects is a factor that has been identified as a major reason for contraceptive non-use, there is a greater scope to improve the quality of service delivery in the FP programme in Botswana.

Acknowledgements The authors would like to thank Statistics Botswana and unicef for allowing them to use the 2007 Botswana Family Health Survey for in-depth analysis. The authors also thank the reviewers for their comments and suggestions, which considerably improved the paper.

Contributors GL conceived and wrote the paper. KN analysed the data. GL and KN both reviewed and approved the final version of the manuscript.

Funding This research received no specific grant from any funding agency in the public, commercial or not-for-profit sectors.
Competing interests None.

Ethics approval The authors used secondary datasets obtained from the national statistical office, Central Statistics Office.

Provenance and peer review Not commissioned; externally peer reviewed.

Data sharing statement No additional data are available.

Open Access This is an Open Access article distributed in accordance with the Creative Commons Attribution Non Commercial (CC BY-NC 4.0) license, which permits others to distribute, remix, adapt, build upon this work noncommercially, and license their derivative works on different terms, provided the original work is properly cited and the use is non-commercial. See: http:// creativecommons.org/licenses/by-nc/4.0/

\section{REFERENCES}

1. United Nations. International Conference on Population and Development. Cairo, 5-13 September 1994, New York, 1995.

2. Canning D, Schultz TP. The economic consequences of reproductive health and family planning. Lancet 2012;380:165.

3. Alkema L, Kantorova V, Menozzi C, et al. National, regional, and global rates and trends in contraceptive prevalence and unmet need for family planning between 1990 and 2015: a systematic and comprehensive analysis. Lancet 2013;381:1642-52.

4. Jain AK, Obare F, RamaRao S, et al. Reducing unmet need by supporting women with met need. Int Perspect Sex Reprod Health 2013;39:133-41.

5. Cleland J, Bernstein S, Ezeh A, et al. Family planning: the unfinished agenda. Lancet 2006;368:1810-27.

6. Casterline JB, Sinding SW. Unmet need for family planning in developing countries and implications for population policy. Popul Dev Rev 2000;26:691-723.

7. Letamo $\mathrm{G}$, Oucho JO. Contribution of family planning program to fertility decline in Botswana. Demogr India 2002;31:79-91.

8. Baakile B, Maribe L, Maggwa BN, et al. A situation analysis of the maternal and child health family planning program in Botswana. Gaborone, Botswana: Ministry of Health, 1996.

9. The World Bank. Fertility decline in Botswana 1980-2006: a case study. 2010.

10. UNICEF. Countdown to Zero. Elimination of new HIV infections among children by 2015 and keeping their mothers alive. Botswana Country Situation (Draft), 2012.

11. Westoff CF, Ochoa LH. Unmet need and the demand for family planning. DHS Comparative Studies, No. 5, Columbia, MD: Institute for Resource Development, 1991.

12. Central Statistics Office and UNICEF. 2007 Botswana Family Health Survey IV Report, 2009

13. Bradley SEK, Croft TN, Fishel JD, et al. Revising unmet need for family planning. DHS Analytical Studies No. 25. Calverton, MD: ICF International, 2012.

14. Cleland J, Harbison S, Shah IH. Unmet need for contraception: issues and challenges. Stud Fam Plann 2014;45:105-22.

15. Horney J. HIV Prevalence and High Contraceptive Prevalence Rates in Botswana, Kenya and Zimbabwe: is this relationship counterintuitive considering the determinants for HIV and CPR and the populations included in prevalence measurements? International Health, University Center for International Studies, The University of North Carolina at Chapel Hill, Carolina Papers, No. 17, 2003.

16. Ross JA, Winfrey WL. Unmet need for contraception in the developing world and the former Soviet Union: an update estimate. Int Fam Plan Perspect 2002;28:138-43.

17. Leburu VM, El-Halabi S, Mokganya L, et al. Contribution of the Botswana Family Planning Program to the Largest Fertility Decline in Sub-Saharan Africa. A report presented at the International Conference on Family Planning: Research and Best Practices, Kamapal, Uganda, 15-18 November, 2009.

18. Sedgh G, Hussain R, Bankole A, et al. Women with an unmet need for contraception in developing countries and their reasons for not using a method, Occasional Report, New York: Guttmacher Institute, No. 37, 2007.

19. Bradley SEK, Schwandt HM, Khan S. Levels, trends, and reasons for contraceptive discontinuation, DHS analytical studies. Calverton, MD: ICF Macro, No. 20. 2009.

20. Adebowale SA, Palamuleni ME. Determinants of unmet need for modern contraception and reasons for non-use among married women in rural areas of Burkina Faso. Afr Popul Stud 2014;28:499-514. 
21. United Nations. Meeting demand for family planning, Department of Economic and Social Affairs, Population Division, 2013, No. 2013/6, December.

22. Sedgh G, Hussain R. Reasons for contraceptive nonuse among women having unmet need for contraception in developing countries. Stud Fam Plann 2014;45:151-69.

23. Ochako $\mathrm{R}$, Mbondo $\mathrm{M}$, Aloo $\mathrm{S}$, et al. Barriers to modern contraceptive methods uptake among young women in Kenya: a qualitative study. BMC Public Health 2015;15:118.

24. Mosha I, Ruben R, Kakolo D. Family planning decisions, perceptions and gender dynamics among couples in Mwanza,
Tanzania: a qualitative study. BMC Public Health 2013;13:523. http://www.biomedcentral.com/1471-2458/13/523

25. Ashford L. Unmet need for family planning: recent trends and their implications for policy, Policy Brief, MEASURE Communication project, 2003

26. Letamo G, Bainame K. Fertility levels, trends and differentials. Botswana Notes and Records (Forthcoming).

27. Republic of Botswana. Revised national population policy. Gaborone: Ministry of Finance and Development Planning, 2010

28. Mason KO. Do population programs violate women's human rights? East-West Center, 1994. 